\title{
SOROCABANA 2014: PAISAGEM SONORA ENATIVA COMO INTERVENÇÃO ESTÉTICA
}

André Luiz Gonçalves de Oliveira, Felipe Fachiolli Pedro

Universidade do Oeste Paulista - UNOESTE. Faculdade de Ciências, Letras e Educação, Presidente Prudente, SP. e-mail: andreluiz@unoeste.br

\section{RESUMO}

As Paisagens Sonoras Enativas foram desenvolvidas a partir de estudos de percepção pela abordagem enacionista da ciência cognitiva e de sua aplicação em procedimentos de composição de Paisagens Sonoras. Apresenta-se a realização de uma intervenção urbana, "Sorocabana 2014", enquanto exemplo de aplicação da perspectiva enativa em Paisagem Sonora. Mostra-se o contexto das Paisagens Sonoras como metodologia empregada para aplicar os conhecimentos advindos dos estudos em percepção, por meio de suas raízes na música eletroacústica, e do caminho dos compositores canadenses da Simon Fraser University. Posteriormente são descritas as etapas de implementação de "Sorocabana 2014", enquanto resultados de propostas com as ideias enativas aplicadas à composição de Paisagens Sonoras. Por fim faz-se uma breve discussão acerca da proposta de subsidiar produção artística com a abordagem enacionista da percepção. E como conclusão aponta-se para algumas outras possibilidades de criação estética que envolvam tal escopo filosóficocientífico.

Palavras-chave: Paisagem Sonora Enativa, Paisagem Sonora, Enacionismo, Ciclo Percepção-Ação.

\section{SOROCABANA 2014: ENACTIVE SOUNDSCAPE AS AESTHETIC INTERVENTION}

\section{ABSTRACT}

The Enactive Soundscapes were developed from studies of perception by enactive approach of cognitive science and its application to procedures of Soundscape composition. This paper presents the realization of an urban intervention, "Sorocabana 2014," as an example of application in enactive perspective of Soundscape creation. We show the context of Soundscapes as used to apply the knowledge derived from studies in perception, through its roots in eletroacoustic music, and the way of canadian composers of Simon Fraser University comprehend and use it. Later stages of implementing "Sorocabana 2014", while results of enactives ideas applied to the composition of Soundscapes were described. Finally we made a brief discussion on the proposal to subsidize artistic production with the enactive approach to perception. And as a conclusion it is stressed some other possibilities of aesthetic creation involving such philosophical-scientific scope.

Keywords: Enactive Soundscape, Soundscape, Enactive Approach to Perception, Perception-Action Cycle. 


\section{INTRODUÇÃO}

Durante um evento de férias da Escola Municipal de Artes Prof. Jupyra Marcondes do município de Presidente Prudente - SP, foi montada uma Paisagem Sonora Enativa ${ }^{1}$, como um tipo de intervenção urbana às margens da linha de trem que encontra-se desativada naquele trecho. Essa linha pertenceu à antiga Companhia Estrada de Ferro Sorocabana, que no início do século XX chegou até Presidente Prudente e foi uma das responsáveis pelo desenvolvimento de todo o interior paulista.

As pessoas que circulavam nos arredores do trecho da ferrovia desativada, nas proximidades do Centro Cultural Matarazzo, ouviam os sons dos trens, como se a ferrovia estivesse ativa novamente. Nesse sentido, o objetivo da experiência era oferecer a paisagem sonora de um mundo que já existiu ali. Oferecer às pessoas a oportunidade de uma experiência passada, de memória, que faz parte das raízes do mundo que aí está hoje. Assim, esse artigo pretende descrever tal experiência de Paisagem Sonora Enativa, bem como tecer explicações e comentários sobre suas implicações na produção de arte contemporânea e suas relações com a filosofia e ciência contemporânea.

\footnotetext{
${ }^{1}$ Enativa diz respeito à abordagem enacionista da cognição e percepção, liderada por autores como Varela , Thompson e Rosh (1991); Maturana (1997) e Noë (2004, 2009).
}

\section{METODOLOGIA}

A intervenção, chamada aqui de Paisagem Sonora Enativa ficou funcionando por cerca de 8 horas ininterruptas. A montagem envolveu dois monitores de som, posicionados em direção à linha do trem separados por cerca de cinquenta metros. Tais monitores (ativos) estavam tocando o resultado de um programa multi-pista que ia sendo montado em tempo real (planejando sempre os próximos 20 minutos) com uma ampla variedade de arquivos com eventos sonoros advindos de estações de trens de diferentes épocas e locais do mundo. ${ }^{2}$

Em um MacBook Pro foi rodado o programa multi-pista Logic com uma janela com 20 canais, nos quais eram inseridos os eventos sonoros do banco de dados. A distância entre os monitores de som permitia a percepção de panorâmicas em estereofonia, fazendo com que as pessoas ouvissem os trens passando de um lado para o outro. Entre os diferentes eventos sonoros do banco de dados estavam ruídos de vários tipos de locomotivas de trens, de diferentes tamanhos de comboios, de diversos tipos de freios, das buzinas de variadas épocas e locais, e de trens passando em velocidades bastantes distintas. Enfim, se buscou criar ali não a reconstrução exata da

\footnotetext{
${ }^{2}$ Esse banco de dados de arquivos com tais eventos sonoros foi fruto de um levantamento e seleção realizado na internet, por meio de sítios eletrônicos como youtube.com e freesound.org.
} 
paisagem sonora da época de funcionamento da Companhia Estrada de Ferro Sorocabana, mas oferecer dados sonoros para a ativação da memória, dos afetos e emoções envolvidas com a existência e funcionamento da companhia.

O que se nomeia aqui por Paisagem Sonora Enativa é concebido enquanto um tipo de intervenção urbana que, por meio da difusão de eventos sonoros, oferece possibilidade de experiência estética. O espectador tem a possibilidade de se locomover em um espaço preparado para perceber diferentes aspectos da experiência. Assim, essa possibilidade permite significações próprias, descritas muito bem pelas teorias filosófico-científicas que serão pontuadas.

\section{RESULTADOS}

Foi por meio da leitura de autores como J. J. Gibson, M. Merleau-Ponty, F. Varela, E. Couchot, e M. Leman, por exemplo, que determinados procedimentos como a disposição dos alto-falantes, a realização da composição da paisagem em tempo real, a mobilidade dos espectadores, foram pensados e implementados.

Instalar alto-falantes em locais públicos tem sido uma ação interessante no sentido de permitir novas experiências estéticas com as Paisagens Sonoras. Tem sido um procedimento que permite entender tais experiências como enativas, no sentido de que possibilitam a ação coletiva (enação) dos espectadores. Transforma o espectador de passivo em ativo, em uma analogia ao que propõe J. J. Gibson (1966) ao entender os orgãos dos sentidos como sistemas perceptivos, que ao invés de serem caracterizados enquanto canais passivos por onde transita a informação, são então descritos como sistemas ativos que buscam padrões altamente elaborados e dispostos no meio em que vivem.

Muitas pessoas experimentaram a paisagem circulando em volta da linha de trem, nas ruas dos bairros do entorno. Desse modo, não tinham campo de visão para alcançar a linha em si e os possíveis trens a passar, mas ouviam os eventos sonoros de toda a movimentação na estação. Outras experimentaram os ruídos do trem caminhando sobre os trilhos. Eles podiam provar a sensação sonora de se encontrar no meio dos trens que passavam de um lado para o outro. Ao caminhar em direção à estação, vindo pela linha de trem, podia-se ouvir toda aquela movimentação sonora se aproximando. Houve também um fluxo de pessoas cruzando a linha de trem, uma vez que desativada, tornou-se atalho bastante usado por quem ali circula a pé. Essas pessoas atravessavam a Paisagem Sonora e em diversos momentos de 
sua caminhada no trecho, buscavam informação visual que desse alguma pista dos sons ouvidos.

Nesse tipo de atividade artística se inverte completamente a atitude do espectador (percebedor) tradicional de música de concerto, preso a uma poltrona confortável o suficiente para que nem ruído da respiração venha a fazer; ou do espectador de arte em uma galeria ou museu, imóvel frente a obra, em atitude de contemplação quase espiritual, um quase transe que o desliga e aliena do mundo que habita no dia-a-dia. ${ }^{3}$

\section{DISCUSSÃO}

O termo Paisagem Sonora foi criado na década de 1970 pelo compositor e educador canadense R. M. Schafer, juntamente com seus companheiros na Universidade Simon Fraser. Schafer (1977) apresenta o conceito de Paisagem Sonora e discorre sobre a importância da compreensão dos sons em relação a vida, tanto em seu local quanto em sua época específicos. Se ja havia desde a década anterior um caminho para o estudo de ambientes acústicos, como em "Silent Spring" de R. Carson (1962), ou mesmo as produções de biólogos ou urbanistas, como Krause (1987)

\footnotetext{
${ }^{3}$ Há um vídeo que mostra imagens da linha de trem e dos eventos sonoros que aconteciam ali: https://www.youtube.com/watch?v=pOS3ruryeWg\&list=UUVJMRafZP Spi RylyviRwjQ.
}

e Southworth (1969), Schafer abre uma imensa gama de possibilidades estéticas.

Paralelamente a isso, a música eletroacústica produzida principalmente por compositores europeus, adiciona novas possibilidades de composição musical. Técnicas de gravação, processamento de sinal e síntese sonora possibilitaram a criação de novas estéticas. É também nesse momento que aparece o conceito de espaço na música, usado de maneira não metafórica. Através da utilização de alto-falantes é possível a distribuição e repetição dos eventos sonoros captados e/ou sintetizados, no espaço, em tempo real ou não. É de se destacar que é a partir do uso da referencialidade que a música eletroacústica vai em direção às Paisagens Sonoras.

A proposta conceitual de MerleauPonty (2002) oferece novo papel para o corpo ao se descrever a percepção, ou seja, formas de ouvir, sentir, emocionar e de significar. É do conceito de estilo como meio de viver (MERLEAU-PONTY, 2002, p.86), que o autor aponta ser decorrente a possibilidade de significação. Na seqüência pode-se ler que: Significação decorre de uma maneira típica de habitar o mundo [...]. (MERLEAU-PONTY, 2002, p.87). Esse habitar o mundo está intimamente relacionado ao desenvolvimento dos hábitos de percepção-ação que fazem a vida do 
organismo no meio. Ao propor que as pessoas movimentem-se para experimentar a paisagem oferece-se um novo tipo de significação, ainda mais se esse movimento se dá no local onde os eventos sonoros acontecem. Algumas significações só ocorrem de fato na medida em que o ouvinte escuta o som do trem se aproximando e está caminhando sobre a linha do trem, na antiga estação, ora desativada.

Merleau-Ponty (1996), Varela, Thompson e Rosch (1991) e Maturana (1997) propõem a noção de percepção como ação perceptivamente orientada, e afirmam também que: [...] cognitive structures emerge from the recurrent sensoriomotor pattern that enable action to be perceptually guided. ${ }^{4}$ (VARELA; THOMPSON; ROSCH, 1991, p.173). Isso é a própria definição de cognição para o enacionismo. A orientação das ações das pessoas ao ouvirem os diversos ruídos de trens enquanto caminhavam sobre os trilhos, ou no entorno deles, permitiu um tipo de cognição e percepção muito específicos daquela experiência. Tal experiência configura-se como algo muito distinto de ouvir o mesmo conjunto de eventos sonoros sentado em uma poltrona. Em último caso, os padrões sensório-motores da movimentação do espectador pela paisagem constituem-se muito distintos

\footnotetext{
${ }^{4}[. .$.$] estruturas cognitivas emergem de padrões sensório-motores$ recorrentes, padrões que permitem à ação ser ${ }^{4}$ perceptivamente orientada. Tradução nossa.
}

daqueles do espectador em repouso em uma poltrona.

Também a percepção será, nessa abordagem, tratada sempre como um ciclo contínuo envolvendo percepção-ação. De maneira muito semelhante à Gibson (1966; 1979), também para Noë (2004) a percepção é uma ação de exploração do meio em busca de padrões informacionais (ou conteúdos virtuais) detectados a partir do desenvolvimento de hábitos suportados por habilidades sensóriomotoras. A relação com ecologia gibsoniana é marcante com o uso do conceito de informação disponível no meio, ou ainda pela descrição de perceber como buscar por tal informação no meio. Ao circular para ouvir diferentes sons na paisagem "Sorocabana 2014" o espectador estava ativo em busca de padrões informacionais (auditivos e visuais, no mínimo) que completassem, ou, continuassem sua experiência estética, enquanto dinâmica de exploração do meio.

O enacionismo de Noë (2004; 2009) evidencia o caráter externalista daquilo que se denomina por mente e consequentemente de seus atributos como a percepção e cognição. De acordo com essa perspectiva o conteúdo de uma experiência encontra-se "fora da cabeça" do percebedor, como uma possibilidade da vida, de ações frente aos eventos do mundo, e não como um conjunto de disparos neuronais, 
ou um conjunto de ações bioquímicas, ou outro modelo matemático qualquer que venha a descrever o funcionamento do corpo como algo isolado do meio. Antes, segundo o autor, a percepção é o modo de encontrar com o fenômeno, com as aparências, acompanhar suas mudanças. E isso fica bastante evidente na constituição da experiência ora apresentada. A Paisagem Sonora Enativa "Sorocabana 2014" necessita dos trilhos de trem de fato, da estação e suas plataformas, enfim, do mundo de fato, para constituir sua experiência. Fosse um poema sinfônico e tudo isso seria resolvido pela fértil imaginação do espectador, como se ela fosse deliberadamente orientada para dar vida a um mundo metafísico, único da experiência estética. Em "Sorocabana 2014" o espectador encontra-se sobre os trilhos de trem, sobre a plataforma, escuta o trem, ruidos possíveis e impossíveis, pode imaginar o que quiser, mas sua experiência está intimamente atrelada ao mundo externo. O conteúdo de sua experiência encontra-se incrustado em seu entorno perceptivo.

\section{CONCLUSÃO}

Ao implementar diferentes conceitos de áreas de conhecimento distintas, como filosofia, ciência cognitiva e psicologia, atividades artísticas, como a que foi aqui apresentada, cumprem um papel já tradicional na história do ocidente. Há muito que se articulam conhecimentos tecnológicos, científicos e artísticos na produção de experiências estéticas. Pode-se citar desde a arte dos gregos de cerca do s. V a.C., passando pela grande intimidade entre revolução científica e Renascimento, ou ainda pela revolução industrial e o lluminismo, e chegando até a arte contemporânea e seu contato intimo com teorias da filosofia, psicologia e ciência cognitiva.

Embora as conclusões sejam iniciais, envolvendo o projeto de pesquisa que motivou o presente texto, elas já apontam para um grande potencial por articular assuntos amplos de áreas distintas. Essa tem sido uma importante marca da pesquisa em arte contemporânea, sua abertura para relação com diversas outras áreas do conhecimento. De maneira geral, mais do que buscar nessas outras áreas apenas instrumentos para realização de idéias artísticas, esse trabalho de pesquisa está orientado para buscar na filosofia e ciências as próprias idéias. Mais ainda, para articular tais idéias em forma de experiência estéticas. 


\section{REFERÊNCIAS}

CARSON, R. Silent spring. Greenwich: Fawcett, CARSON, R. Silent spring. Greenwich: Fawcett, 1962.

GIBSON, J. J. The senses considered as perceptual systems. Boston: Houghton Mifflin, 1966.

GIBSON, J. J. Ecological approach to visual perception. Hillsdate: Lawrence Erlbaum Associates, 1979.

KRAUSE, B. Bioacoustics: habitat ambience and ecological balance. Whole Earth Review, n.57, 1987.

MATURANA, R. H. A ontologia da realidade. Belo Horizonte: UFMG, 1997.

MERLEAU-PONTY, M. Fenomenologia da percepção. São Paulo: Martins Fontes, 1996.

NOË, A. Out of our heads. New York: Hill and Wang, 2009.

NOË, A. Perception in action. BERKELEY: The Mit, 2004.

SCHAFER, R. M. The soudscape: our sonic environment and the tunning of the world. New York: Knopf, 1977.

SOUTHWORTH, M. The sonic environment of cities. Environment and Behaviour, jun. 1969.

VARELA, F. J.; THOMPSON, E.; ROSCH, E. The embodied mind: cognitive science and human experience. Cambridge: MIT, 1991. 